\title{
Leaf Structure of Two Chemotypes of Calophyllum brasiliense from México
}

\author{
H.A. Zavaleta-Mancera*, R. Reyes-Chilpa**, J. Cesar García-Zebadua**
}

*Postgrado de Botánica. Colegio de Postgraduados en Ciencias Agricolas, Montecillo, Edo. Mex. México. Km. 36.5 Carretera México Texcoco (arazavaleta@colpos.mx)

** Instituto de Química, Universidad Nacional Autónoma de México UNAM. Ciudad de México (chilpa@servidor.unam.mx)

Calophyllum (Clusiaceae) species constitute a source of new chemical compounds able to inhibit HIV-1 RT [1]. In the American Continent Calophyllum is represented by 8 species; among them, Calophyllum brasiliense is the widest distributed species from Argentine to Mexico [2]. We have previously reported that two populations of C. brasiliense, from "Santa Martha" and "Los Tuxtlas" Veracruz, Mexico, differ in their leaf chemistry, therefore they are denominated "chemotypes" CTP1 and CTP2 respectively. The CTP1 contains mammea type coumarins, while CTP2 produces chromanones and calanolides; only the second chemotype is active against HIV-1 RT [3, 4]. Chemical differences may be related to a speciation process in this taxon; however morphological, anatomical and DNA sequences may also be examined for supporting this hypothesis. In this contribution we examined if both chemotypes exhibit anatomical differences in their leaves.

Mature leaves from at least 5 threes of CTP1 and CTP2 ecotypes were used for the structural study. Transversal sections ( $2 \mathrm{~cm}$ wide) from the central part of the leaf were fixed in FAA solution $(3.6 \%$ formaldehyde, $5 \%$ acetic acid glacial, $50 \%$ ethanol in water) for $48 \mathrm{~h}$. Then the tissue was rinsed twice with distilled water and dehydrated in an ethanol serial $(50,70,80,90$, $96 \%$ ) and two changes in absolute ethanol for $2 \mathrm{~h}$ each concentration. Tissue was infiltrated in paraffin (Paraplast) [5]. Transversal sections $(15 \mu \mathrm{m})$ of the main vein were obtained in a rotator microtome (Optical instrument) and stained with safranin "O" and fast green FCF [6]. Sections were studied with an optical microscope (Axioscop 2 Plus, Zeiss, Germany) and pictures were captured with a digital camera (Axiocam 5RMs).

The two leaf ecotypes of $C$. brasiliense are bifacial, with palisade mesophyll tissue adaxially and many layers of parenchyma cells in the spongy mesophyll abaxially. The vascular tissue of the lamina is formed by colateral vascular bundles; the xylem facing the adaxial epidermis and the phloem facing the abaxial epidermis. Leaves are hipo-estomatics, estomata are present only in the abaxial epidermis. Despite these overall basic similarities, there is substantial variation in several aspects of leaf anatomy and morphology between the two ecotypes. This include midrib shape, presence or absence of hypodermis, single or double palisade mesophyll layers, distances between secondary veins, abundance of laticiferous and canals, abundance of channels. Leaf blade of CTP2 ecotype is thicker $(300-275 \mu \mathrm{m})$ than Santa Martha $(200-225 \mu \mathrm{m})$ and the epicuticular wax of CTP1 is thicker and contain more tannins than CTP2 leaves. The palisade mesophyll is formed of two layers in CTP2 in contrast CTP1 ecotype shows a hypodermis with thick cell walls and single layer palisade mesophyll; character associated with coriaceous leaves and barriers to dehydration. These characters may be associated with the environmental conditions where this ecotype grows. The mid rib bundle show differences between ecotypes, CTP1 leaves show the adaxial parenchyma convex and the abaxial one is pronounced convex, in contrast CTP2 leaves have adaxial parenchyma of the midribs flat and the abaxial parenchyma is slight convex. The cross sectional shape of the vascular bundle of the midribe show differences: Santa Martha's bundle form a "close U shape" with an average aperture of $60^{\circ}$ in contrast, CTP2 bundle form a "open V shape" with an average aperture of $90^{\circ}$. Lysigenous glands in midribs and lamina are found in both ecotypes. Laticiferous are present in the midrib, particularly abundant in CTP1 ecotype. 
The leaf anatomy study showed structural dereferences between the CPT1 and CPT2. These results support the hypothesis of a speciation process in this taxon, associated with a specific leaf chemistry

\section{References}

[1] Y. Kashman et al., J. Med. Chem. 35 (1992) 2735-2743.

[2] P.F. Stevens, J. Arnold Arbor. 61(1980) 117-171.

[3] M. Huerta-Reyes, et al., Biol. Pharm. Bull. 27(2004) 1471-1475.

[4] R. Reyes-Chilpa and M. Huerta-Reyes, Interciencia 34(2009) 385-392.

[5] S.E. Ruzin. Plant Microtechnique and Microscopy. Oxford University Press. Oxford, New York, (1999).

[6] H. Zavaleta, M.E. Engleman. Phytomorphology 44 (1994): 169-175.

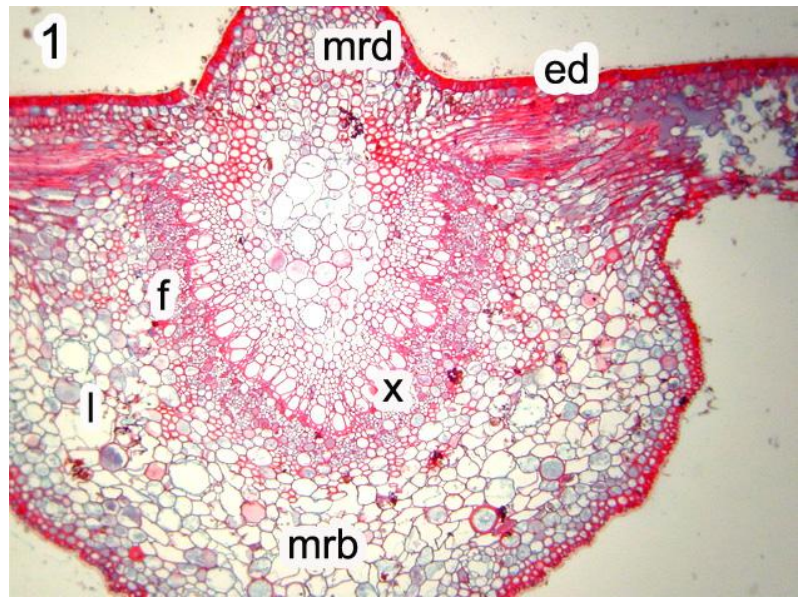

Figure 1. Cross section of C. brasiliense midrib CTP 1 (Santa Martha).

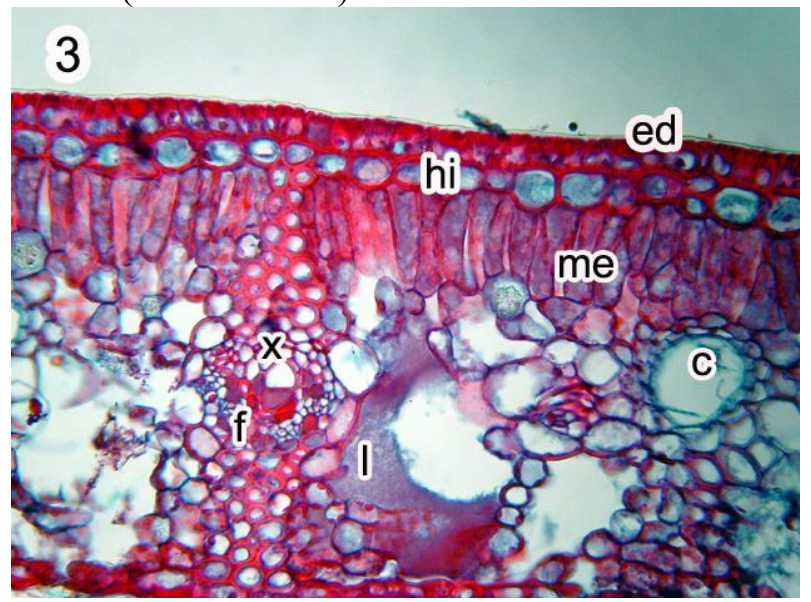

Figure 3. Cross section of $C$. brasiliense lamina of CTP 1 (Santa Martha).

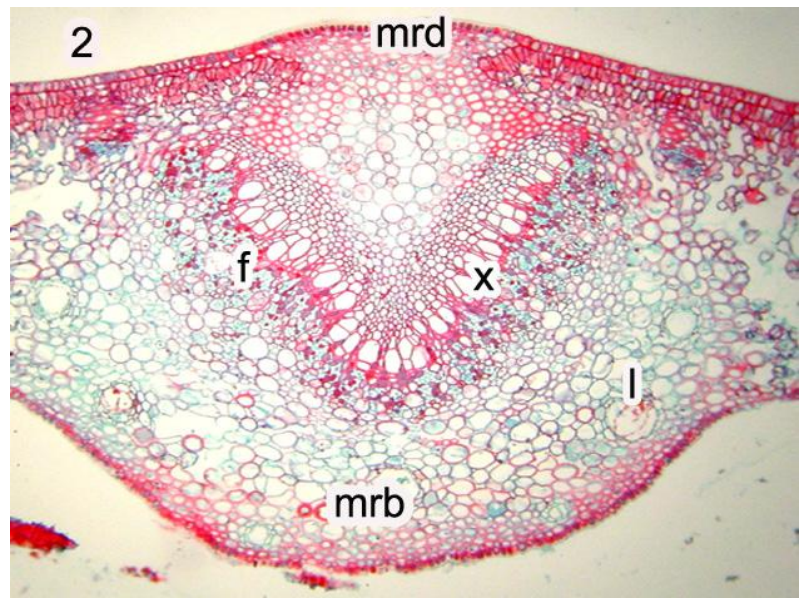

Figure 2. Cross section of C. brasiliense midrib CTP 2 (Los Tuxtlas).

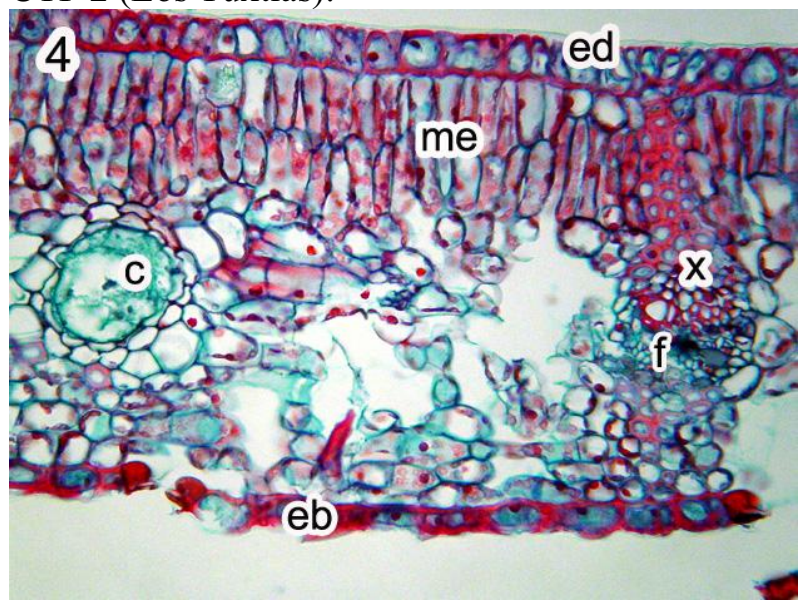

Figure 4 . Cross section of $C$. brasiliense lamina of CTP 2 (Los Tuxtlas).

Labels: ed, adaxial epidermis; eb, abaxial epidermis; $x$, xylem; f, phloem; hi, hypodermis; me, palisade mesophyll; sm, spongy mesophyll; mrb, midribe abaxial; mrd; midrib adaxial; c, chanel; 1, laticiferous. 